\title{
Ageism in the COVID-19 pandemic: age-based discrimination in triage decisions and beyond
}

\author{
Jon Rueda ${ }^{1}$ iD
}

Received: 15 December 2020 / Accepted: 18 June 2021 / Published online: 13 July 2021

(C) Springer Nature Switzerland AG 2021

\begin{abstract}
Ageism has unfortunately become a salient phenomenon during the COVID-19 pandemic. In particular, triage decisions based on age have been hotly discussed. In this article, I first defend that, although there are ethical reasons (founded on the principles of benefit and fairness) to consider the age of patients in triage dilemmas, using age as a categorical exclusion is an unjustifiable ageist practice. Then, I argue that ageism during the pandemic has been fueled by media narratives and unfair assumptions which have led to an ethically problematic group homogenization of the older population. Finally, I conclude that an intersectional perspective can shed light on further controversies on ageism and triage in the postpandemic future.
\end{abstract}

Keywords Ageism $\cdot$ COVID-19 $\cdot$ Triage

\section{Introduction}

The COVID-19 pandemic will leave an indelible mark in the history of triage. ${ }^{1}$ The healthcare collapse has forced extreme rationing of critical resources. Triage practices have not only multiplied, but have also been the focus of heated media discussions. Triage is the process of classifying patients according to their medical needs and severity. Originally, triage was developed by military medicine during the

\footnotetext{
${ }^{1}$ This note belongs to the Topical Collection "Seeing Clearly Through COVID-19: Current and future questions for the history and philosophy of the life sciences", edited by G. Boniolo and L. Onaga. See Boniolo \& Onaga (2021).
}

Jon Rueda

ruetxe@ugr.es; ruetxe@gmail.com

1 Department of Philosophy 1 and FiloLab-UGR Scientific Unit of Excellence, University of Granada, Granada, Spain 
Napoleonic era (Mitchell, 2008; Nakao et al., 2017). Its aim was to classify and prioritize the evacuation of wounded soldiers that could return soon to the battlefield. Today, triage systems are currently used not only in disaster medicine and mass casualty situations, but also in conventional emergency settings at many hospitals and in Intensive Care Unit (ICU) admissions. Triage is necessary, for instance, when the demand (for hospital or ICU beds, or mechanical ventilatory support) greatly exceeds supply.

During the coronavirus pandemic, a controversy has been at the forefront of the public arena: the suspicion of ageism in the allocation of vital medical services. Ageism is an unjustified discrimination based on age. In non-crisis situations, age is already considered in the ordinary distribution of hemodialysis machines, scarce organs, or elective surgeries. During the pandemic, the age criterion has sometimes played a major role. Consider, for instance, the following examples. In Italy, the Italian Society of Anaesthesia, Analgesia, Resuscitation and Intensive Care (SIAARTI) suggested the need for considering an age limit to be admitted to ICU (Vergano et al., 2020). In Spain, the hospital Vall d'Hebron suggested not allocating ventilators to patients older than 80 , and considering the frailty scale of candidates between 70 and 80 (Vall d'Hebron, 2020). More disturbingly, in March 2020, the Regional Government of Madrid developed a protocol establishing a criteria for referral to hospital from nursing homes, which excluded older adults in end-of-life situations and which considered the degree of physical and cognitive disabilities (Rico, 2020). Were these recommendations ethically justified? Or were they ageist?

In this article, I briefly start addressing the core ethical aspects of considering age in triage decisions. First, I analyze the role of age in two important criteria for triage and rationing: benefit and fairness. I defend that, although there are moderate reasons to consider the age of patients in triage decisions, using age as a categorical exclusion is an ethically unjustifiable ageist practice. After that, I show that ageism is based on a problematic group homogenization that has been reinforced during the COVID-19 pandemic. Finally, I argue that an intersectional perspective could help to avoid ageist tendencies and other social discriminations in triage and beyond in the post-pandemic future.

\section{Looking for benefits and fairness in triage: what role should age play?}

A prominent ethical aspiration of triage is to efficiently maximize the benefits of scarce resources. Benefits can be measured in two ways: regarding short-term survival or long-term survival. The former seeks to save lives-basically, being discharged from hospital. The latter, conversely, seeks to save those who can have a longer life expectancy. Typically, this second type of benefit takes into account not only the number of years that can be saved, but also the quality of life of the person that has survived. An elderly person normally obtains a shorter and generally lower quality of long-term survival expectancy compared to a young or middle-aged person. Similarly, in terms of short-term survival, the elderly tend to benefit less from vital resources such as ventilators, since intensive treatments require physical 
endurance that frailer patients sometimes cannot withstand (Nickel et al., 2020). In short, elderly people in general benefit less from critical resources regarding shortterm and long-term survival. Moreover, older adults often need intensive treatments for longer. During the pandemic, at times when the healthcare system collapsed, maximizing benefits could have also justified rationing of ventilators (either withholding or withdrawing them) which gave priority to younger patients based on the predicted time of use of the resource. However, this does not exclude the fact that some healthy elderly individuals could have benefitted more than younger people with greater comorbidities and poorer health. Thus, the clinical judgments of measuring prospective benefits should be individualized to avoid categorical exclusions (Rueda, 2020).

The principle of fairness requires distributing the costs and benefits of medical services in a just manner. According to fairness, the ethical relevance of age can point out in two different directions. On the one hand, from an intergenerational justice perspective, individuals should have the opportunity of living a sufficient and normal life-span-the so-called "fair innings" (see Harris, 1985, chapter 5). Those who are below the agreed threshold (say, about 70 years) should have a higher prima facie priority than those who have already overcome it. In this sense, the life-cycle criterion values the opportunity of going through different vital stages and demands, in a rationing situation, to take into account the age of the candidates to the scarce resources (Emanuel \& Wertheimer, 2006).

Fairness, on the other hand, tries also to avoid placing vulnerable social collectives on systematic disadvantage. Even if there are reasons to consider age in triage decisions, categorically excluding all members of a vulnerable group is blind discrimination (Auriemma et al., 2020; Carrieri et al., 2020; Scully, 2020). Although exceptionally, some elders might benefit more in post-treatment prognosis than competing younger patients. Furthermore, another reason to avoid cut-off exclusions is that age limits are arbitrary and sometimes biased (Rueda, 2020). For instance, the left-digit bias is the tendency to categorize continuous variables according to the leftmost number-e.g., $0,99 €$ seems much cheaper than $1 €$, although the difference is insignificant. Thus, ethical recommendations based on decade thresholds-like that of the Spanish Vall d' Hebron Hospital — can suffer from this type of bias: a 79-year-old patient is considered depending on her fragility status, but an 80-yearold is not, even if the clinical differences between both of them are not relevant. Consequently, this bias has likely affected the allocation of vital medical resources during the pandemic (Nickel et al., 2020).

\section{Looking beyond triage: ageism as a problematic group homogenization}

Although age distinctions may be permissible if they serve the goals of patients care, using age as an exclusion criterion is ethically unacceptable because it differentiates merely according to group membership, which is the "hallmark of unjust discrimination" (Brown et al., 2021, p. 13). In consequence, some group homogenization discourses around age can be potentially problematic. Using age-based exclusion 
criteria for triage has been just the tip of the iceberg of ageism during the COVID19 pandemic.

Ageist narratives have been present in the media at various points during the pandemic. One clear example is the fact that the older population's vulnerability towards COVID-19 has been disproportionately emphasized in comparison to other people with particular conditions (e.g., obesity, heart disease, asthma, or history of smoking) that may also put them in high-risk groups (Reynolds, 2020). This disproportionate messaging has shaped the social view and identity of older adults as a highly vulnerable group. Furthermore, the media coverage has also promoted cases of older adults that have altruistically refused the use of ventilators to give the chance of survival to younger people (see Carriere et al., 2020; Barth et al., 2021). The irreflective promotion of these examples runs the risk of extending simplistic views about the very difficult bioethical topic of whether there is a "duty to die" (see Hardwing, 1997) when one is old and when one competes about scarce healthcare resources with younger patients.

Ageism has also been elicited by unfair assumptions. Age may seem like an objective clinical criterion for triage decisions. However, using age as a diagnostic label is potentially unjust because it obscures the great number of individual variations within each age group (Scully, 2020). In fact, there are cases of nonagenarian and centenarian individuals who have survived COVID-19, even after having been in ICU (see Rueda, 2020; Carrieri et al., 2020). Thus, categorically considering age can perpetuate social injustices and structural disadvantages because it reinforces assumptions about the quality of life, health status, and broad social utility of the older population (Berkhout \& Richardson, 2020; Carrieri et al., 2020; Scully, 2020). These assumptions sometimes are simply false.

Thus, ageism fosters discrimination based on age from a problematic group homogenization. However, older adults should not be considered as a homogenous group (Barth et al., 2021). Indeed, as happens with other social identities such as women, elders do not constitute a uniform demographic group (Berkhout \& Richardson, 2020). This group characterization leads furthermore to the "formation of stereotypes, prejudices and discrimination" against older adults (Barth et al., 2021). It also obscures the structural context of inequalities that permeates aging. Clinical vulnerability to COVID-19 also depends on pre-existing forms of health injustices (Scully, 2020). Consequently, after considering social inequities and the heterogeneity of older people, age alone may become a poor proxy for health outcomes (Brown et al., 2021).

\section{Looking to the post-pandemic future: an intersectional antidote against ageism and other types of discrimination}

Older adults have predominantly experienced ageism during the COVID-19 pandemic (Barth et al., 2021). These experiences have been prompted by negative social perceptions about the older population that include prejudices, false beliefs, or inaccurate stereotypes. Still, individual experiences during the pandemic depend on other social factors that go beyond one's own chronological age. Moreover, 
health-related social factors may also influence variations of individual responses towards COVID-19 in elder people. In that sense, debates about ageism in health justice can be benefited by an intersectional perspective. ${ }^{2}$ Intersectionality remarks the analysis on the overlapping of social positions and identities (Berkhout \& Richardson, 2020). ${ }^{3}$ Considering age alone is inadequate because it fails to differentiate between age itself and other conditions that may have been caused by social determinants of health rather than necessarily by aging.

From an intersectional perspective, age is not the only thing that makes a person benefit less from a scarce life resource. Other social identities play a major role in the health status of older individuals, and of the population in general. Even if agebased cut-offs and exclusions were replaced by an individualized assessment, being a woman or a man, being racialized or non-racialized, abled or disabled, or poor or rich are social factors that may have an impact on the survival prognosis of individuals. Systemic health injustices may put particular individuals at disadvantage because of social identities other than age. Hence, in addition to ageism, it is also necessary to denounce other types of systemic disadvantages and discriminations (such as sexism, ableism, or racism) that may affect triage decisions. ${ }^{4}$ So, although there is no doubt that COVID-19 has disproportionately impacted elders, future research should disaggregate data to study the differential effects that COVID-19 has had on mortality and morbidity according to socioeconomic variables within the older population. Furthermore, another important commitment is to redress ageist discourses in society. Expressed ageist messages during the pandemic may have deleterious consequences in the attitude towards aging and older population long after the pandemic (Reynolds, 2020). Thus, we must not allow pandemic ageism to impact the future well-being and self-esteem of the elderly.

Finally, age needs to be avoided as a categorical exclusion criterion not only because it is ageist, but also because it may decrease public trust in healthcare rationing. According to one experimental survey, there is a public preference to use comprehensive triage criteria instead of categorical characteristics (Rueda et al., 2020). In this sense, using multi-principle triage systems can mitigate unfair discrimination against vulnerable collectives (Auriemma et al., 2020; Rueda, 2020). Moreover, it could also alleviate the devaluation that older individuals may have experienced because of the disproportionate emphasis that has been placed on age. Hopefully, we will learn this lesson for future healthcare crises. During the pandemic, older adults have suffered both from COVID-19 and ageism. It is in our hands to exclude agebased discrimination in future triage decisions.

\footnotetext{
2 Intersectionality is also necessary to avoid age-based discrimination in the economic domain (Burn et al., 2020).

3 The author is a young white man who researches bioethics and ethics of technology. I felt privileged also because my life and job have not been compromised during the pandemic, and because I have recovered from COVID-19 without sequels.

4 It is also important to note how ageism and ableism have intersected in some triage decisions, such as in the nursing home scandal of Madrid (see Rico 2020). In fact, ableism during triage protocols has been another very controversial topic during the pandemic (Savin \& Guidry-Grimes 2020).
} 
Acknowledgements I am indebted to the two anonymous reviewers and to María Jiménez Castro for their helpful comments on the previous versions of the manuscript. I also thank the funding of an INPhINIT Retaining Fellowship of the La Caixa Foundation (Grant number LCF/BQ/DR20/11790005).

\section{References}

Auriemma, C. L., Molinero, A. M., Houtrow, A. J., \& Persad, G. (2020). Eliminating categorical exclusion criteria in crisis standards of care frameworks. The American Journal of Bioethics, 20(7), 28-36. https://doi.org/10.1080/15265161.2020.1764141

Barth, N., Guyot, J., Fraser, S. A., Lagacé, M., Adam, S., Gouttefarde, P., Goethals, L., Bechard, L., Bongue, B., Fundenberger, H., \& Célarier, T. (2021). COVID-19 and quarantine, a catalyst for ageism. Frontiers in Public Health, 9(April), 1-7. https://doi.org/10.3389/fpubh.2021.589244

Berkhout, S. G., \& Richardson, L. (2020). Identity, politics, and the pandemic: Why is COVID-19 a disaster for feminism(s)? History and Philosophy of the Life Sciences, 42(4), 1-6. https://doi.org/10. 1007/s40656-020-00346-7

Boniolo, G., \& Onaga, L. (2021). Seeing clearly through COVID-19: Current and future questions for the history and philosophy of the life sciences. History and Philosophy of the Life Sciences, 43(2), 83. https://doi.org/10.1007/s40656-021-00434-2

Brown, T. R., Francis, L. P., \& Tabery, J. (2021). When is age choosing ageist discrimination? Hastings Center Report, 51(1), 13-15. https://doi.org/10.1002/hast.1205

Burn, I., Button, P., Figinski, T. F., \& McLaughlin, J. S. (2020). Why retirement, social security, and age discrimination policies need to consider the intersectional experiences of older women. Public Policy and Aging Report, 30(3), 101-106. https://doi.org/10.1093/ppar/praa017

Carrieri, D., Peccatori, F. A., \& Boniolo, G. (2020). COVID-19: A plea to protect the older population. International Journal for Equity in Health, 19(1), 5-8. https://doi.org/10.1186/s12939-020-01193-5

Emanuel, E. J., \& Wertheimer, A. (2006). Who should get influenza vaccine when not all can? Science, 312(5775), 854-855. https://doi.org/10.1126/science.1125347

Hardwig, J. (1997). Is there a duty to die? Hastings Center Report, 27(2), 34-42.

Harris, J. (1985). The value of life: An introduction to medical ethics (p. 2001). Routledge.

Mitchell, G. W. (2008). A brief history of triage. Disaster Medicine and Public Health Preparedness, 2(Suppl 1), S4-S7. https://doi.org/10.1097/DMP.0b013e3181844d43

Nakao, H., Ukai, I., \& Kotani, J. (2017). A review of the history of the origin of triage from a disaster medicine perspective. Acute Medicine and Surgery, 4(4), 379-384. https://doi.org/10.1002/ams2. 293

Nickel, C. H., Ruegg, M., Pargger, H., \& Bingisser, R. (2020). Age, comorbidity, frailty status: Effects on disposition and resource allocation during the COVID-19 pandemic. Swiss Medical Weekly, 150, w20269. https://doi.org/10.4414/smw.2020.20269

Reynolds, L. (2020). The COVID-19 pandemic exposes limited understanding of ageism. Journal of Aging and Social Policy, 32(4-5), 499-505. https://doi.org/10.1080/08959420.2020.1772003

Rico, M. (2020). Los seis documentos que demuestran que Ayuso miente sobre la orden de no trasladar enfermos de residencias a hospitales (Six documents that prove Ayuso is lying about the order not to transfer patients from nursing homes to hospitals). InfoLibre, 5 May 2020. Available at: https://www.infolibre.es/noticias/politica/2020/06/05/los_seis_documentos_que_desmontan_versi on_ayuso_sobre_orden_no_trasladar_enfermos_residencias_hospitales_107433_1012.html (Last Accessed 16 May 2021).

Rueda, J., Hannikainen, I., Hortal, J., \& Rodríguez-Arias, D. (2020). Examining public trust in categorical versus comprehensive triage criteria. The American Journal of Bioethics, 20(7), 106-109. https://doi.org/10.1080/15265161.2020.1779867

Rueda, J. (2020). ¿No es país para viejos? La edad como criterio de triaje durante la pandemia COVID19 (No Country for old men? Age as a triage criteria during COVID-19 pandemic). Enrahonar. An International Journal of Theoretical and Practical Reasoning, 65, 85-98. https://doi.org/10.5565/ rev/enrahonar.1306

Savin, K. \& Guidry-Grimes, L. (2020). Confronting disability discrimination during the pandemic. The Hasting Center Bioethics Forum Essay, 2 April 2020. Available at: https://www.thehastingscenter. org/confronting-disability-discrimination-during-the-pandemic/ (Last Accessed 16 May 2021). 
Scully, J. L. (2020). Disability, disablism, and COVID-19 pandemic triage. Journal of Bioethical Inquiry, 17(4), 601-605. https://doi.org/10.1007/s11673-020-10005-y

Vall d'Hebron (2020). Recomanacions per suport a les decisions d'adequació de l'esforç terapèutic (AET) per pacients amb sospita d'infecció per COVID-19 insuficiència respiratòria aguda (IRA) hipoxèmica (Recommendations for supporting the limitation of therapeutic effort decisions for patients with suspected hypoxemic acute respiratory insufficiency COVID-19 infection). Grup de treball de Ventilació, Cap Àmbit Emergències, Direcció Mèdica i Direcció Infermera de SEM, 25 March 2020. Retrieved from: https://coronavirus.coib.cat/wp-content/uploads/2020/03/recomanaci ons-suport-decisions-aet.pdf. (Last Access: 15 December 2020).

Vergano, M., Bertolini, G., Giannini, A., Gristina, G., Livigni, S., Mistraletti, G., Riccionin, L., \& Petrini, F. (2020). Clinical ethics recommendations for the allocation of intensive care treatments in exceptional resource-limited circumstances. Minerva Anestesiologica, 86(5), 469-472. https://doi.org/10. 23736/S0375-9393.20.14619-4

Publisher's Note Springer Nature remains neutral with regard to jurisdictional claims in published maps and institutional affiliations. 